\title{
Treatment of Autoimmune Neuromuscular Diseases with High-Dose Intravenous Immune Globulin
}

\author{
SHAWKE A. SOUEIDAN AND MARINOS C. DALAKAS \\ Neuromuscular Diseases Section, National Institute of Neurological Disorders and Stroke, National Institutes of \\ Health, Bethesda, Maryland 20892
}

\begin{abstract}
The majority of autoimmune neuromuscular diseases fall into three groups: 1) The autoimmune neuropathies, which include the acute inflammatory demyelinating polyneuropathy (Guillain-Barré syndrome), the chronic inflammatory demyelinating polyneuropathy, the paraproteinemic polyneuropathies, and the anti-GM1-associated motor neuropathies with conduction block; 2) the inflammatory myopathies, which include the dermatomyositis and polymyositis complex; and 3 ) the autoimmune neuromuscular junction defects, which include myasthenia gravis, and the Lambert-Eaton myasthenic syndrome. Laboratory and clinical evidence suggests that circulating antibodies or sensitized lymphocytes are operating in the pathogenesis of these conditions. Current immunotherapies include treatment with plasmapheresis, high-dose steroids, or immunosuppressive drugs. Although all of these therapies are effective in a number of patients and for some period of time, they often result in serious side effects that necessitate their discontinuation. The need for safer and more effective therapies in the treatment of these conditions prompted the use of high-dose i.v. immune globulin (IVIG). A number of small trials and a few reports suggest that IVIG is safe and effective in the treatment of patients with autoimmune neuropathies, inflammatory myopathies, and myasthenia gravis unresponsive to conventional therapies. We will present current experience with IVIG in the abovementioned autoimmune neuromuscular diseases, and we will stress the need for long-term controlled studies. The possible immunomodulatory action of IVIG in these conditions will also be discussed. (Pediatr Res 33 (Suppl): S95-S100, 1993)
\end{abstract}

Abbreviations

IVIG, intravenous immune globulin

AChR, acetylcholine receptor

CIDP, chronic inflammatory demyelinating polyneuropathy

DM, dermatomyositis

GBS, Guillain-Barré syndrome

MG, myasthenia gravis

PE, plasma exchange

PM, polymyositis

EAMG, experimental autoimmune myasthenia gravis

NIH, National Institutes of Health

Correspondence: Marinos C. Dalakas, M.D., Chief, Neuromuscular Diseases Section, Building 10, Room 4N248, NINDS, National Institutes of Health, Bethesda, MD 20892.

\section{RATIONALE FOR USE OF IVIG}

Recent advances in the use of high-dose IVIG in a number of autoimmune disorders (1-3) has led to the application of such therapy in neuromuscular diseases. These diseases are of presumed dysimmune or autoimmune pathogenesis and include inflammatory neuropathies, inflammatory myopathies, and autoimmune neuromuscular junction defects. The most accepted treatment for all these disorders, with the exception of GBS, is corticosteroid therapy given in high doses and for long periods of time in an attempt to induce remissions or halt the progression of the disease (4-9). Other immunosuppressive agents, which include azathioprine, cyclophosphamide, cyclosporine, and methotrexate, have also been used, with only limited success, however $(6,9,10)$. The use of these drugs, including steroids, is restricted not only by their limited effectiveness but also by the significant side effects that accompany long-term therapy. PE has also been used in these disorders and is beneficial in GBS $(11,12)$ and MG $(7,10)$ but is not as helpful in CIDP (13). Plasmapheresis is ineffective in PM/DM (5). When PE is used early in the course of GBS, it reduces the time that patients are ventilator-dependent and shortens the time to recovery. Acute exacerbations of myasthenia are also effectively treated with PE, and patients routinely undergo $\mathrm{PE}$ around the time of their thymectomies. The use of PE is, however, limited due to technical difficulties such as hemodynamic instability, especially in the elderly with autonomic dysfunction, and poor venous access, particularly in children. The serious side effects from immunosuppressive drugs and the limitations of PE further underscore the need for more effective and safe therapies.

An appraisal of the effectiveness of IVIG in the treatment of these diseases is currently warranted because few studies have been controlled. A review of the treatment trials with IVIG should provide guidelines for the use of this new treatment modality and directions for future research. The actual mode or modes by which IVIG exerts its effect are not clear but do depend on the immunopathogenic mechanism operating in each disease. Identifying how IVIG exerts its effects, particularly its rapid onset of action in certain autoimmune neuromuscular diseases, hinges on understanding the immunopathogenesis of these disorders. They all share similar autoimmune abnormalities, be it circulating antibodies as in $\mathrm{MG}$, altered cellular and humoral immunity as it appears to be in GBS and CIDP, IgG immune complexes or complement-mediated microangiopathy as seen in DM, or a combination of these abnormalities.

\section{MG}

MG is probably the prototypic antibody-mediated autoimmune disease to a well-characterized receptor, the acetylcholine nicotinic receptor ( $\mathrm{AChR}$ ). The immunopathogenesis of $\mathrm{MG}$ has been reviewed recently $(7,14)$ and is summarized in Table 1. 
Table 1. Immunopathogenesis of $M G$

1. Antibodies against $\mathrm{AChR}$

Present in up to $90 \%$ of patients

Lead to complement-mediated lysis of the receptors and accelerate their degradation

AChR is the target antigen

2. Circulating $T$ cells are sensitized to the $A C h R$ and may regulate antibody response

3. Passive transfer experiments

4. Hyperactive thymus gland

5. Experimental allergic $M G$

Table 2. Studies of IVIG therapy in $M G$

\begin{tabular}{|c|c|c|}
\hline & Responders & $\begin{array}{c}\text { AChR antibody } \\
\text { titer }\end{array}$ \\
\hline Fateh-Moghadam et al..$^{17}$ & $8 / 9$ & Decreased \\
\hline Gadjos et al..$^{15,16}$ & $10 / 21$ & Decreased \\
\hline Ippoliti et al. ${ }^{18}$ & $5 / 7$ & Same \\
\hline Arsura et al. ${ }^{14}$ & $11 / 12$ & Same \\
\hline Uchiyama et al. $^{22}$ & $0 / 6$ & Same \\
\hline Cook et al..$^{23}$ & $5 / 5$ & Same \\
\hline Lombardi et al..$^{20}$ & $17 / 27$ & $\mathrm{ND}^{*}$ \\
\hline Isolated cases & $4 / 4$ & Same \\
\hline Total & $60 / 91$ & \\
\hline
\end{tabular}

*ND, not determined.

The role of the antibodies to AChR in the pathogenesis of MG is well established. The antibody first binds to one or more epitopes of the AChR; this leads to a number of possible events that in turn cause destruction or enhanced degradation of AChR. A decrease in the available number of receptors causes failure of the neuromuscular transmission and results in muscle weakness. Serum IgG from myasthenic patients can transmit the disease in mice. The animal model, EAMG, has greatly enhanced our understanding of the immunopathogenesis of MG. In EAMG, accelerated degradation of the receptor occurs as a result of crosslinking adjacent molecules by bivalent $\mathrm{IgG}$ in the absence of complement. The role of cytotoxic $T$ cells is unclear; however, $\mathrm{T}$ cells appear to play an immunoregulatory role in the disease. Moreover, the thymus gland is hyperplastic or thymomatous, hypersecretes thymic hormones, and contains $\mathrm{AChR}$ in its myoid cells. Furthermore, thymectomy facilitates the patient's improvement or causes complete remission.

Treatment of MG with immune globulin was first reported in 1984, when five patients were treated with high-dose IVIG over a 5-d period and all had a favorable response (15). Since the original report, approximately 91 patients with MG have received IVIG as part of small, uncontrolled clinical trials or case reports $(15-26)$. The duration of therapy as well as dosing regimens differed between trials, making it difficult to draw definitive conclusions by combining the results of heterogeneous clinical trials. Also, different preparations have been used, which may contain varying amounts of monomeric IgG and $F\left(a^{\prime}\right)_{2}$ fragments. The nature of the preparation may have some ramification as to the efficacy of the drug, particularly as it pertains to the mechanism of action of IVIG in MG. These considerations aside, it appears that about $65 \%$ of the treated patients have responded to a single course of high-dose IVIG (14) (Table 2). In the single study that did not show any efficacy (22), six patients were treated with an IVIG dose of $10 \mathrm{~g} / \mathrm{d}$ for $3 \mathrm{~d}$, a dose much lower than the recommended dosing schedule used by all others. In most studies that reported a response, improvement appeared within $3 \mathrm{wk}$ and may be noted as early as $2 \mathrm{~d}$ after the infusion. Duration of the response was variable and seemed to be longer if the patients were receiving concomitant steroids (14). This stresses the possibility that IVIG may have a role as an adjunctive therapy in MG, rather than primary therapy. None of these studies investigated the role of IVIG as a disease course-modify- ing drug. Certainly, this was not possible, inasmuch as a single dose was used and MG is a condition characterized by fluctuations. Clinical response did not correlate with AChR antibody titer, and only two groups of investigators reported a decline in the titer along with clinical improvement $(15-17,24)$. In a few case reports, repeated courses were needed to maintain improvement; however, the authors did not comment on any change in the course of the disease.

A number of possible mechanisms have been proposed recently $(27,28)$ that could explain the mode of action of IVIG. These mechanisms are summarized in Table 3 . The direct effect on antibody-binding site, which would have been suspected in a disease such as MG, has not been demonstrated conclusively, and down-regulation of autoantibody production has been shown in only some patients $(15-17,24)$. Recent evidence suggests that the primary mode of action of IVIG in antibodymediated autoimmune disorders is through idiotypic-antiidiotypic interactions $(1-3,27-32)$. This was elegantly demonstrated by Sultan et al. (33) in autoimmune factor VIIII:C deficiency. The role of antiidiotypes is not as clear in $M G$, but experimental evidence indicates that whole IVIG or $F\left(a b^{\prime}\right)_{2}$ fragments from IVIG preparations neutralize AChR antibodies in vitro (34). Furthermore, monoclonal antiidiotypes are therapeutic in EAMG induced by specific AChR epitopes (35). Spontaneously occurring antiidiotypes may have a regulatory role in the pathogenesis of MG $(36,37)$. Their role in the sera of asymptomatic family members of MG patients is controversial, but one questions how prevalent these antibodies are in the general population (38). Another mechanism proposed for the action of IVIG is Fc receptor blockade. The basis for this proposal is the observation that a beneficial response was obtained from infusions of $7 \mathrm{~S}$ but not $5 \mathrm{~S}$ IVIG $(17,24)$.

\section{INFLAMMATORY NEUROPATHIES}

A number of recent studies have provided insight into the pathogenesis of inflammatory demyelinating polyneuropathies $(6,8,9,39-48)$. The immunopathogenesis of GBS is reviewed by Rostami (this issue). The principal proposed mechanisms are summarized in Tables 4 and 5. The electrophysiologic principle of weakness in GBS or CIDP, at least early in the disease, is the conduction block produced when a portion of the axon fails to transmit impulses in a segment where myelin has been destroyed or rendered nonfunctional. Antibodies or autoaggressive cytotoxic $\mathrm{T}$ cells block myelin components, or saltatory conduction at the nodes of Ranvier may be responsible for this phenomenon.

Table 3. Proposed mechanisms of action of IVIG in autoimmune neuromuscular diseases

1. Immunomodulation by $F c$ receptor blockade

2. Idiotypic/antiidiotypic interactions

3. Down-regulation of autoantibody production

4. Direct effect on antibody-binding site on nerve, muscle, or neuromuscular junction

5. Solubilization of immune complexes

6. Possible action on natural killer or suppressor cells

Table 4. Autoimmune basis of Guillain-Barré syndrome

1. Antibodies to peripheral nerve antigens

2. Complement-fixing antimyelin antibodies

3. Abnormal regulatory cells

$\mathrm{T}$ cells recognize nerve antigens

Activated, IL-2-positive T cells

4. Tissue immunopathology

MHC expression

Macrophage-mediated demyelination

Ig and complement deposits

5. Passive transfer of demyelination

6. Experimental allergic neuritis 
Table 5. Autoimmune basis of CIDP

1. Antibodies to peripheral nerve antigens

2. Abnormal immunoregulatory cells

$T$ cells recognize nerve antigens

Activated, IL-2-positive T cells

3. Tissue immunopathology

MHC expression

Macrophage-mediated demyelination

Ig and complement deposits

4. Association with HLA-Aw30, Aw31, B8, Dw3

To understand the immunomodulatory effect of IVIG, one must identify the mechanisms by which myelin is destroyed. More importantly, one has to be able to explain the rapid onset of action of IVIG, which cannot be due to remyelination of demyelinated segments. Rather, there must be one or more factors responsible for conduction failure. The most likely processes are humoral, such as antibodies against myelin, which can lead to complement activation $(41,43)$. Autoantibodies to various myelin antigens have been identified in patients with GBS, CIDP, and paraproteinemic neuropathies $(41,47,49)$. Although the exact pathogenic role of these antibodies is not clear, some of the antibodies in GBS fix complement and their titer does correlate with disease activity (41). In the animal model, experimental allergic neuritis, it was shown that complement is deposited in the vicinity of blood vessels and around the myelin at 11 $\mathrm{d}$ postinoculation with myelin antigens and before demyelination is observed (45). The membranolytic attack complex or terminal component of complement (C5b-9) was identified by immunohistochemical methods in the above-mentioned areas, implying a direct role for complement-mediated damage to the nerves (45). Past studies have also demonstrated deposition of complement components in the nerve biopsies of patients with GBS and CIDP as well as activated components in the sera and spinal fluid of such patients $(39,42-44)$.

The first case of response to plasma infusion was reported in 1981 , by Maas et al. (50), in a patient with a relapsing remitting demyelinating polyneuropathy. The patient was treated with varying doses of steroids and azathioprine for $5 \mathrm{y}$ before PE was attempted. Fresh-frozen plasma was administered as replacement fluid, and the patient had a dramatic response within $1 \mathrm{wk}$ of treatment. Another infusion of fresh-frozen plasma, without PE, 3 wk later, resulted in improvement that was similar to that noted after the PE alone. The dramatic response observed after this plasma infusion prompted a trial of high-dose IVIG in a number of patients with CIDP. A review of the literature reveals that, to date, 86 patients with GBS, 101 patients with CIDP, and two patients with paraproteinemic neuropathy have been treated with IVIG (50-66). The only truly controlled study was the Dutch GBS trial. One hundred fifty patients were randomized to receive high-dose IVIG or PE. This study, which was published recently, concluded that IVIG appears to be superior to PE in the treatment of GBS: $52.7 \%$ of patients in the IVIG group were improved at 4 wk versus $34.2 \%$ of patients in the PE group (67). In this study, IVIG was not compared to no treatment at all. One interesting finding from the study is that treatment-related fluctuations or early relapses were noted with equal frequency in both IVIG-treated and PE-treated groups (59). Treatment-related fluctuations have been used previously as an argument to support the autoimmune mechanism of GBS and the efficacy of PE as an immunomodulating agent in this disease. It can be speculated that a similar argument may apply for the role of IVIG. Three of the 11 patients who had an early relapse and who had received immune globulin responded to another course of high-dose IVIG. Other small series and case reports of patients with GBS also indicate a favorable response to IVIG therapy $(58,60)$.

IVIG therapy in CIDP has not been as rigorously investigated. Its efficacy has been reported in approximately 101 patients since 1981 (50-57, 61-66), but only one study of seven patients was partially controlled (56). It is difficult to draw conclusions on the efficacy of IVIG based on these reports because of 1) lack of control data, 2) heterogeneity of the patients studied regarding degree of conduction block, concomitant axonal loss, or other associated illness, and 3) lack of consensus on how CIDP is best defined. With these limitations in mind, it appears that up to $70 \%$ of patients improve. Benefit is usually noticeable within the first week and occasionally within hours after beginning the infusion and may last up to $6 \mathrm{wk}$. In one retrospective analysis of 53 patients, $40 \%$ of those who had a favorable response to IVIG required repeat infusions to maintain improvement (54). The authors of this report felt that if patients had disease of less than $1-y$ duration with ongoing progression and significant demyelination by electrophysiology there was a $93 \%$ probability of improvement with IVIG. Whether these criteria will hold true in larger controlled studies remains to be seen. One other study reported a placebo-controlled, crossover treatment trial of seven patients with CIDP that had previously responded to IVIG. These patients were randomized to receive high-dose IVIG or placebo. The results indicate a beneficial effect of IVIG in all of these patients; however, the sample was already preselected and thus biased the study (56). Clinical response was accompanied by electrophysiologic improvement in a number of patients, but electrical studies were not uniformly required to define benefit $(55,57)$. A double-blind, randomized, placebo-controlled study is now ongoing at the NIH.

The paraproteinemic polyneuropathies specifically have not been studied systematically, but some of the reports discussed above included patients with CIDP who had associated gammopathies. We reported on two patients who have been treated since 1988. Both patients responded to high-dose IVIG; one improved $3 \mathrm{wk}$ after the first course and the other after the second monthly infusion. Both have continued to benefit from IVIG and continue to receive monthly infusions. A double-blind study is now ongoing at the NIH for paraproteinemic polyneuropathies.

The proposed immunomodulating properties of IVIG responsible for the beneficial effect in demyelinating neuropathies are as diverse as in any other autoimmune disease $(68,69)$. Recently, VanDoorn and colleagues $(70,71)$ reported that whole IVIG or $\mathrm{F}\left(\mathrm{ab}^{\prime}\right)_{2}$ fragments neutralize antibodies to the neuroblastoma cell line detected in patients with CIDP, implying an idiotype/antiidiotype interaction. These antibodies are reportedly present in $42 \%$ of patients with GBS and CIDP, but not in healthy adults or in patients with other neurologic diseases (47). Their significance in the pathogenesis of CIDP and GBS or their role as markers of disease activity remains unknown. Of interest, however, was the observation that postrecovery sera from patients with GBS neutralized the anti-neuroblastoma cell line activity in the prerecovery sera of other GBS and CIDP patients $(70,71)$. This implies that spontaneously occurring antiidiotypes may exist in patients with GBS and may even have a protective role in the natural progression of the disease. The observation that postrecovery-sera antiidiotypes from GBS patients cross-reacted with antibodies from CIDP patients may provide some insight into the source of the antiidiotypes present in IVIG. One can envision that such protective antibodies may be naturally prevalent in subclinical cases of GBS. Other anti-peripheral nerve antibodies have also been detected in patients with inflammatory neuropathies and include anti-GM1, anti-myelin-associated glycoprotein, and antiglucolipids (49). Healthy adults also have low titers of such anti-peripheral nerve antibodies, which may be the stimulus for the cross-reactive antiidiotypes responsible for the efficacy of IVIG $(49,72)$. Another explanation is the solubilization of immune complexes by the IVIG or the competition with complement-binding, anti-peripheral nerve antibodies.

\section{INFLAMMATORY MYOPATHIES}

Inflammatory myopathies can be differentiated based on clinical and histologic criteria (73). Whereas DM is well defined 
clinically by the typical rash and pattern of weakness, PM is more heterogeneous and essentially is a diagnosis of exclusion requiring the need to search for drug systema, toxic, metabolic, autoimmune, or familial neuromuscular disorders that may mimic its presentation. Both diseases may be suspected in individuals who are genetically predisposed to develop such an autoimmune disease. The pathogenesis of these disorders was recently reviewed (73) and is summarized in Tables 6 through 8 . Humoral and cell-mediated immunopathogenic mechanisms are operating in both DM and PM. DM is primarily a humorally mediated microangiopathy that leads to muscle ischemia or infarcts. Deposition of the membranolytic attack complex C5b9 , presumably by antibodies bound to microvascular components, appears to be the earliest lesion preceding inflammation and deposited in the areas of the muscle that still appear intact (74). Those same areas are underperfused and probably responsible for the early signs of muscle weakness. It is very likely that these lesions may be amenable to reversal with IVIG therapy and may explain the rapid recovery occasionally reported in DM with such treatment. The endomysial inflammatory cellular infiltrate consists predominantly of $\mathrm{CD} 4+>\mathrm{CD} 8+$ cells. B cells are also present. In contrast, PM is not due to a microangiopathy but rather to a T-cell-mediated cytoxic process that is MHC restricted $(73,75-78)$. In PM, healthy muscle fibers are surrounded or invaded by cytotoxic CD8+ or gamma-delta $T$ cells $(77,78)$. The role of autoantibodies is not clear in either DM and PM because they are nonspecific.

Roifman et al. (79) first reported the use of IVIG in inflammatory myopathies in 1987 . In 1991, two reports $(80,81)$ appeared that showed that IVIG was helpful in PM and DM patients. Both were open-label, uncontrolled studies, and a total of 25 patients were treated. The treatment consisted of monthly infusions of high-dose IVIG for a mean duration of 4 mo in one study (80) and 9 mo in the other (81). Overall, including the case reports $(80,82), 92 \%$ of patients with DM and $73 \%$ of patients with PM have responded to IVIG (Table 9). A beneficial response was noted within the first week after treatment in some cases, whereas in others it was not noted until after the second infusion, indicating a potential cumulative effect. One can only speculate on the mechanism of action of IVIG in these two diseases, inasmuch as no studies have been conducted to answer this question. In DM, an early response can certainly be due to solubilization of immune complexes that induce the complement deposition in the microvasculature. A reversal of the earliest ischemic lesion can "rescue" the muscle before infarction ensues.

Table 6. Immunopathogenesis of inflammatory myopathies $(P M$ and $D M)$
1. Circulating autoantibodies
Against nuclear antigens
Against cytoplasmic antigens
2. Association with certain viral infections
3. Association with HLA-B8, DR3

Table 7. Immunopathogenesis of DM

Humoral-mediated mechanisms based on

1. Increased endosomysial B-cell infiltrates with $\mathrm{CD} 4+$ cells $>\mathrm{CD} 8+$ cells

2. Deposition of Ig and complement in endosomysial vessels

3. Microangiopathy mediated by the C5b-9 membraneolytic attack complex (earliest lesion)

Table 8. Immunopathogenesis of PM

Cellular-mediated mechanisms

1. Cytotoxic CD8+ $T$ cells surround healthy muscle fibers

2. Strong expression of MHC-1 antigen in nonnecrotic muscle fibers

3. Lymphocytes are cytotoxic to autologous myotubes

4. Disease can be mediated by $\gamma / \delta \mathrm{T}$ cells
Table 9. IVIG therapy in inflammatory myopathies

\begin{tabular}{|c|c|c|c|}
\hline & \multicolumn{2}{|c|}{$\begin{array}{l}\text { Patients } \\
\text { responded }\end{array}$} & \multirow{2}{*}{$\begin{array}{c}\text { Duration } \\
\text { (mo) }\end{array}$} \\
\hline & $\mathrm{PM}$ & DM & \\
\hline Cherin et al. ${ }^{80}$ & $10 / 14$ & $5 / 6$ & $1-24$ \\
\hline Lang et al. ${ }^{81}$ & & $5 / 5$ & $2-18$ \\
\hline Bodemer et al ${ }^{82}$ & & $1 / 1$ & $?$ \\
\hline Roifman et al $^{79}$ & $1 / 1$ & & $?$ \\
\hline Total & $11 / 15$ & $11 / 12$ & \\
\hline
\end{tabular}

Other mechanisms listed in Table 3 could also explain the longterm benefit noted in these two studies, in which the duration of the response ranged from 1 to $24 \mathrm{mo}$.

\section{CONCLUSIONS}

We provide evidence supporting the conclusion that high-dose IVIG is beneficial in autoimmune-related neuromuscular disorders. With the exception of GBS, however, all of these studies are uncontrolled and preliminary. The mechanism of action of IVIG in these diseases remains largely unexplained. The direct effect on antibody-binding sites, which would be most operative in a disease like $\mathrm{MG}$, has not really been demonstrated, and down-regulation of autoantibody production has been shown in only some patients. The possibility of idiotypic/antiidiotypic interaction is an attractive explanation for the beneficial effect in patients with MG, CIDP, and GBS.

The current role of IVIG as the first line therapy or adjunct therapy as a steroid-sparing agent in all of these conditions remains to be defined. Clearly, in GBS the evidence is overwhelming that IVIG compares favorably with PE. In the pediatric age group, in which PE may be impractical, IVIG should be the drug of choice in treating GBS and it should be considered in treating CIDP and MG. IVIG may prove to have a greater role as an adjunctive therapy to other immunosuppressive drugs, especially during exacerbations such as those seen with MG and CIDP. In PM and DM, IVIG appears also to be effective; however, only a double-blind, placebo-controlled trial, such as the one being conducted currently at the NIH, will provide the definitive answer. HIV-infected subjects represent another group of patients who suffer from autoimmune neuromuscular diseases and who may benefit from IVIG therapy.

\section{REFERENCES}

1. Dwyer JM 1992 Manipulating the immune system with immune globulin. $\mathrm{N}$ Engl J Med 326:107-116

2. Etzioni A, Pollack S 1989 High-dose intravenous immunoglobulins in autoimmune disorders: mode of action and therapeutic uses. Autoimmunity 3:307315

3. Newland AC, Macey MG, Veys PA 1991 Intravenous immunoglobulin: mechanisms of action and their clinical application. In: Imbach P (ed) Immunotherapy With Intravenous Immunoglobulins. Academic Press, London, pp $15-26$

4. Dalakas MC 1990 Inflammatory myopathies. Curr Opin Neurol Neurosurg 3:689-696

5. Dalakas MC 1989 Treatment of polymyositis and dermatomyositis. Curr Opin Rheumatol 1:11:3-449

6. Dalakas MC, Engel WK 1981 Chronic relapsing (dysimmune) polyneuropathy: pathogenesis and treatment. Ann Neurol 9:134-145

7. Levinson AI, Zweiman B, Lisak RP 1987 Immunopathogenesis and treatment of myasthenia gravis. J Clin Immunol 7:187-197

8. Arnason BGW 1987 Autoimmune neuropathies. Ann NY Acad Sci 505:313318

9. Lisak RP, Brown MJ 1987 Acquired demyelinating polyneuropathies. Semin Neurol 7:40-48

10. Dau PC, Lindstrom J, Cassel CK, Denys EH, Shev EE, Spitler LE 1979 Plasmapheresis and immunosuppressive drug therapy in myasthenia gravis. N Engl J Med 297:1134-1140

11. McKhann GM, Griffin JW, Cornblath DR, Quaskey SA, Mellits ED 1988 Role of therapeutic plasmapheresis in the acute Guillain-Barre syndrome. J Neuroimmunol 20:297-300

12. The Guillain-Barre Study Group 1985 Plasmapheresis and acute GuillainBarré syndrome. Neurology 35:1096-1104

13. Dyck PJ, Daube J, O'Brien P, Pineda A, Low PA, Windebank AJ, Swanson C 
1986 Plasma exchange in chronic inflammatory demyelinating polyradiculoneuropathy. N Engl J Med 314:461-465

14. Arsura LA, Aaron B, Brunner NG, Grob D 1988 Effects of repeated doses of intravenous immunoglobulin in myasthenia gravis. Am J Med Sci 295:438443

15. Gajdos $\mathrm{Ph}$, Outin H, Elkharrat D, Brunel D, de Rohan-Chabot P, Raphael JC, Goulon M, Glulon-Goeau C, Morel E 1984 High-dose intravenous gammaglobulin for myasthenia gravis. Lancet $1: 406-407$

16. Gajdos Ph, Outin HD, Morel E, Raphael JC, Goulon M 1987 High-dose intravenous gamma globulin for myasthenia gravis: an alternative to plasma exchange? Ann NY Acad Sci 505:842-844

17. Fateh-Moghadam A, Wick M, Beisinger U, Geursen RG 1984 High-dose intravenous gammaglobulin for myasthenia gravis. Lancet 1:848-849

18. Ippoliti G, Cosi V, Piccolo G, Lombardi M, Mantegaz R 1984 High-dose intravenous gammaglobulin for myasthenia gravis. Lancet 2:809-810

19. Ibars IB, Ponseti J, Espanol T, Matias-Guiu, Codina-Puiggros A 1987 Highdose intravenous immunoglobulin therapy for myasthenia gravis. J Neurol 234-363

20. Lombardi M, Piccolo G, Erbetta A, Cosi V 1991 Efficacy of high-dose intravenous immunoglobulin in 27 myasthenic patients. In: Imbach $P$ (ed) Immunotherapy With Intravenous Immunoglobulins. Academic Press, London, pp 460-461

21. Sakano T, Hamasaki T, Shimizu H, Harada Y, Ueda K 1988 High-dose intravenous immunoglobulin for myasthenia gravis. Hiroshima J Med Sci 37:7-9

22. Uchiyama M, Ichikawa Y, Takaya M, Moriuchi J, Shimizu H, Arimori S 1987 High-dose gammaglobulin therapy of generalized myasthenia gravis. Ann NY Acad Sci 505:868-871

23. Cook L, Howard JF, Folds JD 1988 Immediate effects of intravenous IgG administration on peripheral blood $B$ and $T$ cells and polymorphonuclear cells in patients with myasthenia gravis. J Clin Immunol 8:23-31

24. Beisinger UA, Fateh-Moghadam A, Knorr-Held S, Wick M, Kissel H, Albiez M 1987 Immunomodulation in myasthenia gravis by high-dose intravenous 7-S immunoglobulins. Ann NY Acad Sci 505:828-831

25. Arsura LA, Aaron B, Brunner NG, Namba T, Grob D 1986 High-dose intravenous immunoglobulin in the management of myasthenia gravis. Arch Int Med 146:1365-1368

26. Arsura E 1989 Experience with intravenous immunoglobulin in myasthenia gravis. Clin Immunol Immunopathol 53:S170-S179

27. Nydegger UE 1991 Hypothetic and established mechanisms of therapy with immunoglobulin G. In: Imbach P (ed) Immunotherapy With Intravenous Immunoglobulins. Academic Press, London, pp 37-46

28. Zweiman B 1989 Theoretical mechanisms by which immunoglobulin therapy might benefit myasthenia gravis. Clin Immunol Immunopathol 53:S83-S91

29. Kazatchine MD 1990 Anti-idiotypic suppression of autoantibodies with highdose intravenous immunoglobulins. Apheresis 411-414

30. Burdette S, Schwartz RS 1987 Current concepts: immunology idiotypes and idiotypic networks. N Engl J Med 317:219-224

31. Berchtold P, McMillan R 1991 Intravenous immunoglobulin: new aspects of mechanism of action in chronic ITP. In: Imbach P (ed) Immunotherapy With Intravenous Immunoglobulins. Academic Press, London, pp 245-252

32. Dietrich G, Rossi F, Sultan Y, Kaveri S, Nydegger UE, Kazatchine MD 1991 IVIG and regulation of autoimmunity through the idiotypic network. In: Imbach P (ed) Immunotherapy With Intravenous Immunoglobulins. Academic Press, London, pp 3-14

33. Sultan Y, Kazatchine MD, Nydegger U, Rossi F, Dietrich G, Algiman M 1991 Intravenous immunoglobulin in the treatment of spontaneously acquired factor VIII:C inhibitors. Am J Med 91:35S-39S

34. Liblau R, Gajdos Ph, Bustarret A, El Habib R, Bach JF, Morel E 1991 Intravenous $\gamma$-globulin in myasthenia gravis: interaction with anti-acetylcholine receptor autoantibodies. J Clin Immunol 11:128-131

35. Souroujon MC, Fuchs S 1987 Anti-idiotypic antibodies in the regulation of experimental autoimmune myasthenia gravis. Ann NY Acad Sci 505:676682

36. Lefvert AK, Holm G, Pirskanen R 1987 Autoanti-idiotypic antibodies in myasthenia gravis. Ann NY Acad Sci 505:133-154

37. Eng H, Lefvert AK 1989 Idiotypic network in myasthenia gravis. Clin Exp Rheumatol 3(suppl):S75-S79

38. Dwyer DS, Bradley RJ, Urquhart CK, Kearney JF 1983 Naturally occurring anti-idiotypic antibodies in myasthenia gravis patients. Nature 301:609-614

39. Dalakas MC, Engel WK 1980 Immunoglobulin and complement deposits in nerves of patients with chronic relapsing polyneuropathy. Arch Neurol 37:637-640

40. Feeny DJ, Pollard JD, Mcleod JG, Stewart GJ, Doran TJ 1990 HLA antigens in chronic inflammatory demyelinating polyneuropathy. J Neurol Neurosurg Psychiatry 53:170-172

41. Koski CL 1987 Complement-fixing antiperipheral myelin antibodies and C9 neoantigens in serum of patients with Guillain-Barre syndrome: quantitation, kinetics, and clinical correlation. Ann NY Acad Sci 505:319-325

42. Koski CL, Sanders ME, Swoveland PT, Lawley TJ, Shin ML, Frank MM, Joiner KA 1987 Activation of terminal components of complement in patients with Guillain-Barré syndrome and other demyelinating neuropathies. J Clin Invest 80:1492-1497

43. Monaco S, Bonetti B, Ferrari S, Moretto G, Nardelli E, Tedesco F, Mollnes TE, Nobile Orazio E, Manfredinin E, Bonazzi L, Rizzuto N 1990 Complement-mediated demyelination in patients with IgM monoclonal gammopathy and polyneuropathy. N Engl J Med 322:649-652
44. Sanders ME, Alexander EL, Koski Cl, Shin ML, Sano Y, Frank MM, Joiner KA 1988 Terminal complement complexes (C5b-9) in cerebrospinal fluid in autoimmune nervous system diseases. Ann NY Acad Sci 540:387-388

45. Stoll G, Schmidt B, Jander S, Toyka KV, Hartung HP 1991 Presence of the terminal complement complex (C5b-9) precedes myelin degradation in immune-mediated demyelination of the rat peripheral nervous system. Ann Neurol 30:147-155

46. Toyka KV, Hartung HP, Scafer B, Heininger K, Fierz W 1988 Immune mechanisms in acute and chronic inflammatory polyneuropathies. $J$ Neuroimmunol 20:277-281

47. Van Doorn PA, Brand A, Vermeulen M 1987 Clinical significance of antibodies against peripheral nerve tissue in inflammatory polyneuropathy. Neurology 37:1798-1802

48. Van Doorn PA, Shreuder GM, Vermeulen M, d'Amaro J, Brand A 1991 HLA antigens in patients with chronic inflammatory demyelinating polyneuropathy. J Neuroimmunol 32:133-139

49. Pestronk A, Li F, Griffin J, Feldman EL, Cornblath D, Trotter J, ZHu S, Yee WC, Phillips D, Peeples DM, Winslow B 1991 Polyneuropathy syndromes associated with serum antibodies to sulfatide and myelin-associated glycoprotein. Neurology 41:357-362

50. Maas AIR, Busch HFM, Van Der Heul C 1981 Plasma infusion and plasma exchange in chronic idiopathic polyneuropathy. N Engl J Med 303-344

51. Vermuelen M, Van Doorn PA, Lundkvist Y, Brand A 1991 IVIG treatment in chronic inflammatory demyelinating polyneuropathy. In: Imbach $\mathrm{P}$ (ed) Immunotherapy With Intravenous Immunoglobulins. Academic Press, London, pp 351-358

52. Vermeulen M, Van Der Meché, Speelman JD, Weber A, Busch HFM 1985 Plasma and gamma-globulin infusion in chronic inflammatory polyneuropathy. J Neurol Sci 70:317-326

53. Vedanarayanan VV, Kandt RS, Lewis DV, DeLong GR 1991 Chronic inflammatory demyelinating polyradiculoneuropathy of childhood: treatment with high-dose intravenous immunoglobulin. Neurology 41:828-830

54. Van Doorn PA, Vermeulen MD, Brand A, Mulder GH, Busch HFM 1991 Intravenous immunoglobulin treatment in patients with chronic inflammatory demyelinating polyneuropathy: clinical and laboratory characteristics associated with improvement. Arch Neurol 48:217-220

55. Van Der Meché FGA, Vermeulen M, Busch HFM 1989 Chronic inflammatory demyelinating polyneuropathy conduction failure before and during immunoglobulin or plasma therapy. Brain 112:1563-1571

56. Van Doorn PA, Brand A, Strengers PFW, Meulstee J, Vermeulen M 1990 High dose intravenous immunoglobulin treatment in chronic inflammatory demyelinating polyneuropathy: a double-blind, placebo-controlled, crossover study. Neurology 40:209-212

57. Teasley JE, Parry GJG, Sumner AJ, Garcia C, Malamut RI, Erlemeier SA 1990 Electrophysiologic studies in patients with chronic inflammatory demyelinating polyneuropathy treated with intravenous immune globulin. Muscle Nerve 13:853-854(abstr)

58. Shahar E, Murphy EG, Roifman CM 1990 Benefit of intravenously administered immune serum globulin in patients with Guillain-Barré syndrome. J Pediatr 116:141-144

59. Kleyweg RP, Van Der Meché FGA 1991 Treatment-related fluctuations in Guillain-Barré syndrome after high-dose immunoglobulins or plasma exchange. J Neurol Neurosurg Psychiatry 54:957-960

60. Kleyweg RP, Van Der Meché FGA, Meulstee J 1988 Treatment of GuillainBarré syndrome with high-dose gammaglobulin. Neurology 38:1639-1641

61. Faed JM, Day B, Pollock M, Taylor PK, Nukada H, Hammond-Tooke GD 1989 High-dose intravenous human immunoglobulin in chronic inflammatory demyelinating polyneuropathy. Neurology 39:422-425

62. Curro Dossi B, Tezzon F 1987 High-dose intravenous gammaglobulin for chronic inflammatory demyelinating polyneuropathy. Ital J Neurol 8:321326

63. Cornblath DR, Chaudhry V, Griffin JW 1991 Treatment of chronic inflammatory demyelinating polyneuropathy with intravenous immunoglobulin. Ann Neurol 30:104-106

64. Cook D, Dalakas M, Galdi A, Biondi D, Porter H 1990 High-dose intravenous immunoglobulin in the treatment of demyelinating neuropathy associated with monoclonal gammopathy. Neurology 40:212-214

65. Cook JD, Delgado MR, Soutter-Glass D 1987 Treatment of childhood autoimmune polyneuropathy: III. Gamma globulin. Neurology 37:253(abstr)

66. Albala M, McNamara ME, Sokol M, Wyshock E 1987 Improvement of neurologic function in chronic inflammatory demyelinating polyradiculoneuropathy following intravenous gammaglobulin infusion. :Arch Neurol 44:248-249

67. Van Der Meché FGA, Schmitz PIM, and The Dutch Guillain-Barré Study Group 1992 A randomized trial comparing intravenous immune globulin and plasma exchange in Guillain-Barré syndrome. N Engl J Med 326:11231129

68. Van Doorn PA, Rossi F, Brand A, Van Lint M, Vermeulen M, Kazatchine MD 1990 On the mechanism of high-dose intravenous immunoglobulin treatment of patients with chronic inflammatory demyelinating polyneuropathy. J Neuroimmunol 29:57-64

69. Brand A, Van Doorn PA, Rossi F, Kazatchine MD, Vermeulen M 1990 The mechanism of action of intravenous immunoglobulin in patients with chronic inflammatory demyelinating polyneuropathy. Apheresis 405-409

70. Van Doorn PA, Brand A, Vermeulen M 1988 Anti-neuroblastoma cell line antibodies in inflammatory demyelinating polyneuropathy: inhibition in vitro and in vivo by IV immunoglobulin. Neurology 38:1592-1595 
71. Lundkvist I, Van Doorn PA, Vermeulen M, Van Lint M, Van Rood JJ, Brand A 1989 Regulation of autoantibodies in inflammatory demyelinating polyneuropathy: spontaneous and therapeutic. Immunol Rev 110:105-117

72. Vrethem M, Skogh T, Berlin G, Holmgren H, Ernerudh J 1991 Antibodies to peripheral nerve myelin may occur without clinical neuropathy in healthy persons. J Neuroimmunol 32:219-222

73. Dalakas MC 1991 Polymyositis, dermatomyositis and inclusion-body myositis N Engl J Med 325:1487-1498

74. Kissel JT, Halterman RK, Rammohan KW, Mendell JR 1991 The relationship of complement-mediated microvasculopathy to the histologic features and clinical duration of disease in dermatomyositis. Arch Neurol 48:26-30

75. Zuk JA, Fletcher A 1988 Skeletal muscle expression of class II histocompatability antigens (HLA-DR) in polymyositis and other disorders with an inflammatory infiltrate. J Clin Pathol 41:410-441

76. Rosenberg NL, Kotzin BL 1989 Aberrant expression of class II MHC antigens by skeletal muscle endothelial cells in experimental autoimmune myositis. J Immunol 142:4289-4294

77. Hohlfeld R, Engel AG, li K, Harper MC 1991 Polymyositis mediated by T lymphocytes that express the gamma/delta receptor. N Engl J Med 324:877881

78. Engel AG, Arahata K, Emsilie-Smith A 1990 Immune effector mechanisms in inflammatory myopathies. In: Waksman BH (ed) Immunologic Mechanisms In Inflammatory Myopathies. Raven Press, New York, pp 141-157

79. Roifman CM, Schaffer FM, Wachsmuth SE, Murphy G, Gelfand EW 1987 Reversal of chronic polymyositis following intravenous immune serum globulin therapy. JAMA 258:513-515

80. Cherin P, Herson S, Wechsler B, Piette JC, Bletry O, Coutellier A, Ziza JM Godeau P 1991 Efficacy of intravenous immunoglobulin therapy in chronic refractory polymyositis and dermatomyositis: an open study with 20 adult patients. Am J Med 91:162-168

81. Lang BA, Laxer RM, Murphy G, Silverman ED, Roifman CM 1991 Treatmen of dermatomyositis with intravenous gammaglobulin. Am J Med 91:169172

82. Bodemer C, Teillac D, Le Bourgeous M, Weschsler B, De Prost Y 1990 Efficacy of intravenous immunoglobulins in sclerodermatomyositis. $\mathrm{Br} \mathrm{J}$ Dermato 123:545-546

\section{FLOOR DISCUSSION}

Dr. Schwartz: Do you have any perception as to whether it is necessary to have the high-dosage regimen for efficacy, or would some of the lower-dosage regimens be suitable in terms of this whole spectrum of autoimmune neuropathies? Have you gleaned anything that suggests a trend or is there any evidence for one or the other?

Dr. Soueidan: From reviewing the subject and from our limited clinical experience, I feel that the high-dose IVIG is the one that is effective. Whether that is given over a 2-d course as we give it or over a 4- or 5-d course I do not think makes a difference.

Dr. Schwartz: How about duration of effect?

Dr. Soueidan: The two paraproteinemic patients have been given infusions every 3 to $4 \mathrm{wk}$, and that is how we have been managing the patients in our study. That seems to be the experience of most people. We treated one of the patients with weekly infusions of a quarter of the dose, but that did not seem to be as effective as a high-dose infusion given once a month.

Dr. Schwartz: Have you had anyone or been aware of anyone in whom there has been a "cure" and no need for further treatment?

Dr. Soueidan: I am not aware of such patients. That may be an important issue to study, and this is why I feel that IVIG may be an adjunctive treatment, at least in dosage order.

Dr. Levinson: Is any thought being given to trials using a combined approach with IVIG and plasmapheresis? That approach might be particularly useful in a disease like MG, which we know is mediated by autoantibodies. You have talked about the interesting possibilities of antiidiotypic antibodies being involved and we know complement is involved, so plasmapheresis might have something to do with the antibodies and IVIG might have some effect on the antibodies, B cells, or complement deposition. Any thought being given to that kind of approach?

Dr. Soueidan: That goes back to one of the questions that was asked by Dr. Schwartz. If IVIG does turn out to have a disease course-modulating effect, then a combination therapy might seem logical. At the present time that type of therapy is not available. I know Dr. Van Doorn had treated one of his patients with both PE and IVIG and showed that that patient did well. Now whether that patient did better than on IVIG alone or on $\mathrm{PE}$ alone, he did not elaborate. 